Nevșehir Bilim ve Teknoloji Dergisi TARGíd Özel Sayı 236-242 2016

DOI: 10.17100/nevbiltek.210996

URL: http://dx.doi.org/10.17100/nevbiltek.210996

\title{
Buğday Ekili Alanlarda Agregat Stabilitesine Etki Eden Faktörlerin Belirlenmesi
}

İlknur Gümüş *, Cevdet Şeker, Hamza Negiş, Hasan Hüseyin Özaytekin, Emel Karaarslan, Ümmühan Çetin

Selçuk Üniversitesi Ziraat Fakültesi, Toprak Bilimi ve Bitki Besleme Bölümü, Kampus/KONYA

Öz

Agregat stabilitesi değeri; toprakların yapısal gelişiminde etkili olan bir indikatördür. Topraklar yapısal olarak farklılıklar göstermektedir ve bu yapısal farklılıklar çeşitli faktörler ile uyarılmaktadır. Toprak kil çeşitliliği ve miktarları, $\mathrm{CaCO}_{3}$ içerikleri, katyon değişim kapasitesi, kolloidal demir ve alüminyum oksitler, mikroorganizmalar, ıslanma-kuruma, donma-çözülme ve toprak işleme, toprak yapısının oluşmasında başlıca faktörlerdir. Toprakların yapısal oluşumunda bu faktörlerin etkileri birbirinden oldukça farklıdır.Yapılan bu çalışmanın amacı; Konya ili Çumra ilçesinde Alibey serisi olarak tanımlanmış toprakların agregat stabiliteleri ile buna etki eden faktörler arasındaki ilişkiyi açıklamaktır. Bu amaçla 0-20 cm derinlikten alınan 27 adet toprak örneği çeşitli fiziksel ve kimyasal analizlere tabi tutulmuş ve bulunan sonuçlar istatistiki olarak değerlendirilmiştir. Toprakların tekstürü kil (C), killi tın (CL) ve kumlu killi tın (SCL) sınıfinda yer almakta, agregat stabilitesi değerleri ise \%5,91 ile \%41,40 arasında değişmektedir. Çalışma alanı topraklarının agregat stabilitesi ile tekstür, organik madde, kireç, $\mathrm{Ca}, \mathrm{Mg}, \mathrm{Na}$ ve $\mathrm{K}$ değerleri arasında istatistiksel olarak önemli ilişkiler bulunmuştur. Söz konusu topraklarda agregasyonu artırmak için toprak üzerinde mekanizasyon faaliyetlerin minimum düzeyle sınırlandırılması, organik madde miktarının arttırılması ve toprak agregasyonuna olumsuz etkisi olabilecek her türlü faaliyetin azaltılması gerekmektedir.

Anahtar Kelimeler: Agregat stabilitesi, buğday, toprak özellikleri

\section{Determination of Factors Affecting The Aggregate Stability in Wheat Cultivated Field}

\section{Abstract}

Aggregate stability is an index of the structural stability of the soil. Soil show differences in structural formation and these structural differences are induced by different factors. Soil clay variety and amounts, $\mathrm{CaCO}_{3}$ contents, cation exchange capacity, colloidal iron and aluminiumoxides, microorganims, wetting-drying, freezing-thawing and soil cultivation are the main factors in the formation of the soil structure. Furthermore effects of these factors on the structural formation of soils are quite different from each other.The aim of this study was to determine the effects of some soil properties on aggregate stability in Konya-Çumra plain (Alibey serie). For this purpose soil samples were collected from 27 points and 0-20 cm depth. The samples were analyzed for some soil parameters such as aggregate stability and particle size distribution, organic matter, $\mathrm{CaCO}_{3}, \mathrm{Ca}, \mathrm{Mg}, \mathrm{Na}, \mathrm{K}$ contents using standard routine laboratory tests. The textures of the soil samples were found to be C, CL and SCL. The soil aggregate stability ranged from 5,91 to 41,40\%. The result indicated that particle size distribution, organic matter, CaCO3, Ca, Mg, Na, K contents significantly affected aggregate stability.

As a result, it is required to increase the organic matter content and to reduce the agricultural practices to the minimum tillage in order to increase aggregate stability in the research soils.

Keywords: Aggregate stability, wheat, soil properties

* e-mail: ersoy@selcuk.edu.tr 


\section{Giriş}

Gelişen ekonomi ve artan nüfusun ortaya çıkardığı ihtiyaçlar tarım arazilerinin üzerindeki faaliyetleri artırmakta ve sürdürülebilir tarımsal üretimi olumsuz olarak etkilemektedir.

Toprak fiziksel özelliklerinin geliştirilmesi ve iyileştirilmesi bitki yetiştiriciliği ve toprak koruma açısından oldukça önemlidir. Bitki gelişme ortamı olarak ideal bir toprak, tohumun çimlenebilmesi, filizin yüzeye çıkabilmesi ve bitki kök sisteminin gelişme ve fonksiyonlarını yerine getirebilmesi için gerekli olan çevre koşullarını sağlamaktadır. Böyle bir toprak bu işlevleri yaparken yalnızca bitki gelişimi için gerekli bitki besin maddelerini sunmakla kalmayıp, aynı zamanda bitkinin fonksiyonlarını yerine getirebilmesi için gerekli olan uygun bir hava-su düzenini de sağlamaktadır. Bu durum, toprağın iyi bir strüktüre sahip olmasıyla gerçekleşebilmektedir.

Birçok durumda bitki tarafindan topraktan besin elementi alımı, suyun noksanlık ve fazlalığı, oksijen yetersizliği, ya da toprak sıkışması nedeniyle yetersiz kök gelişimi tarafından sınırlandırılmaktadır. Bütün bunlar uygun olmayan toprak strüktürünün bitki üretiminde sınırlayıcı bir etmen olduğunu, bu bakımdan strüktürün, toprağın sürdürülebilirliğinin bir parametresi olarak dikkate alınması gerektiğini ortaya koymaktadır. Toprak strüktürü, kum, kil ve silt gibi teksel tanelerin toprak içindeki diziliş şekillerini ifade etmektedir. Agregat ise, sekonder ünite içerisinde sıkı bir şekilde yanyana dizilmiş çok sayıda teksel tanelerden meydana gelmiştir. Teksel tanelerin kümeleşmesi sonucunda agregat oluşmaktadır. Toprak strüktürü yönünden agregat oluşumu için, kümeleşen tanelerin birbirleri ile çimentolaşmaları veya bağlanmaları gerekir [1]. Toprakların kil tipi ve miktarı, toprak organik maddesi, toprakların kireç $\left(\mathrm{CaCO}_{3}\right)$ içeriği, katyon değişim kapasitesi, kolloidal demir ve alüminyum oksitler, mikroorganizmalar, 1slanma-kuruma, donma- çözülme olayları ve toprak işleme agregat stabilitesi üzerine etkili olan faktörler arasında yer almaktadır. Topraklarda agregat büyüklük dağılımı ve dayanıklılığı toprak kalitesinin bir göstergesidir [2]. Toprakta iyi bir agregatlaşma ile hava ve su dengesi sağlanmış, köklerin rahatça gelişebilecekleri bir ortam meydana getirilmiş olur. İyi bir agregatlaşma, suyun toprak profili içerisindeki hareketini ve infiltrasyonu engelleyici etkileri ortadan kaldırarak yüzey akışı ile ortaya çıkan kayıpları azaltır [3]. Agregat stabilitesi değeri erozyona uğrama derecesini gösteren önemli bir faktördür [4].

Türkiye'deki tarım alanlarının yaklaşık \%10’u büyük Konya Ovasında (Konya, Çumra, Karaman, Karapınar, Ereğli ve Bor Ovaları) yer almaktadır. Burada bulunan Çumra Ovası ise yüksek tarım potansiyeli ile 280.000 ha'lık bir alana sahiptir [5-6]. Çumra Ovasının verimliliğinin devam ettirilmesi, onun sürdürülebilir kullanımı ve özelliklerinin geliştirilmesi ile mümkün olacaktır. Bu ise toprağın fiziksel, kimyasal, biyolojik ve pedolojik özelliklerini göz önüne alan yaklaşımlar ve buna dayalı çözümlemeler ortaya koyan yöntemler ile mümkün olacaktır.

Bu çalışmada; Konya ili Çumra ilçesinde Alibey serisi olarak tanımlanmış toprakların agregat stabiliteleri ile buna etki eden faktörler arasındaki ilişki açıklanmaya çalışılmışıır.

\section{Materyal ve Metot}

Çalışma alanı, Büyük Konya Ovası içerisinde yer alan, Çumra Ovası'nda, sulu tarım yapılan ve verimlilik potansiyeli yüksek, yaygın toprak serilerinden biri olan Alibey Serisi olarak adlandırılmış alan üzerinde yürütülmüştür (Şekil 1). 
Gümüş İ., Şeker C., Negiş H., Özaytekin HH., Karaarslan E., Çetin Ü.

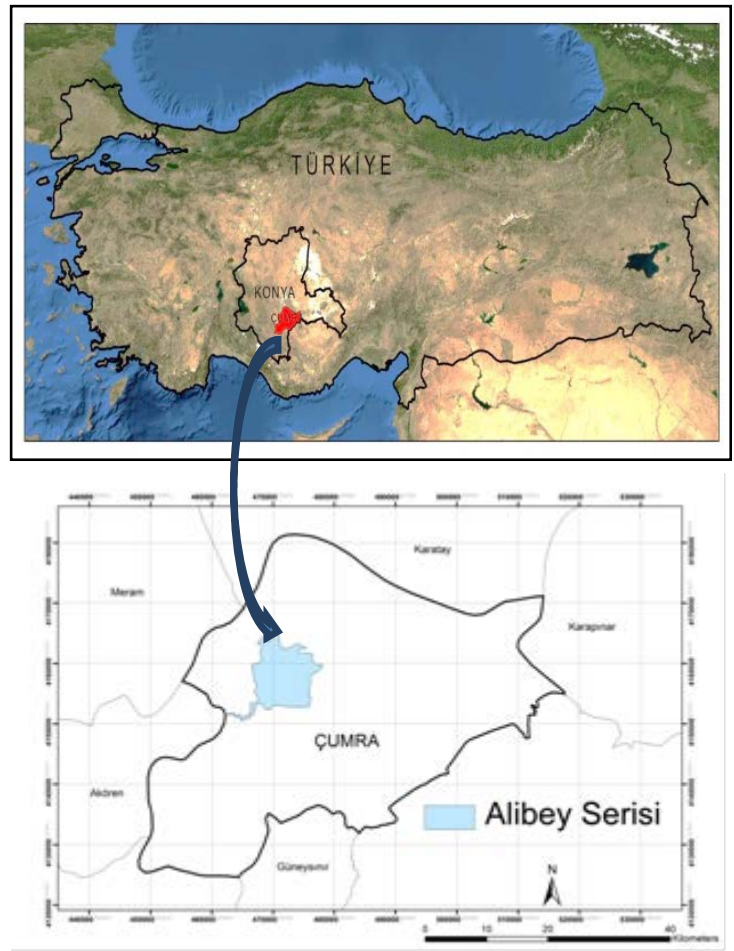

Şekil 1. Çalışma alanının coğrafi konumu

Çalışma arazisi fizyoğrafik olarak homojen, düz alüviyal ova yapısındadır. Çalışma alanı olarak seçilen Alibey serisi; May nehri aluviyal yelpazesi toprakları. Alüviyal anamateryal üzerinde oluşmuş, derin tın tekstürlü topraklar. Çarşamba çayının ovaya ilk girdiği ve eğimin ilk azalmaya başladığı seri. Alanı 4000 ha olup, sulu tarım yapılan Çumra ovasının \% 6'sını temsil etmektedir. Çalışma, arazi çalışmaları ile toprak örneklerinin alınması, toprak örneklerine ait agregat stabilitesi değerlerinin belirlenmesi uygulamaları olmak üzere iki farklı aşamadan oluşmuştur. Çalışma alanından tesadüfi örnekleme ile belirlenen 27 noktadan toprak örnekleri alınmıştır. Araziden alınan toprak örnekleri kurutulup ögütüldükten sonra, $2 \mathrm{~mm}$ 'lik elekten elenerek analize hazır hale getirilmiştir. Toprak örneklerinin agregat stabilitesi değerinin belirlenmesinde "yapay yağış simülatörü“ kullanılmıştır [7-8]. Mekanik analiz Bouyoucos Hidrometre yöntemi [9], organik madde CN LECO cihazı ile Dumas metoduna göre [10], ekstrakte edilebilir katyonlar (Ca, Mg, Na ve K) pH'sı 7'ye ayarlanmış $1 \mathrm{~N}$ amonyum asetat çözeltisi kullanılarak atomic absorbsiyon cihazında belirlenmiştir [11].

İstatistiksel değerlendirmeler Minitab paket programı kullanılarak yapılmıştır [12].

\section{Sonuçlar ve Tartış̧a}

Çalışma alanı agregat stabilitesi değerleri ve tekstür gruplarına ait nokta bazlı alansal dağılım haritası Co-Kriging metodu kullanılarak CBS ortamında üretilmiş $\left(r^{2}=0.87\right.$ modelin ürettiği doğruluk katsayısı) ve Şekil 2 ve 3'de gösterilmiştir. 


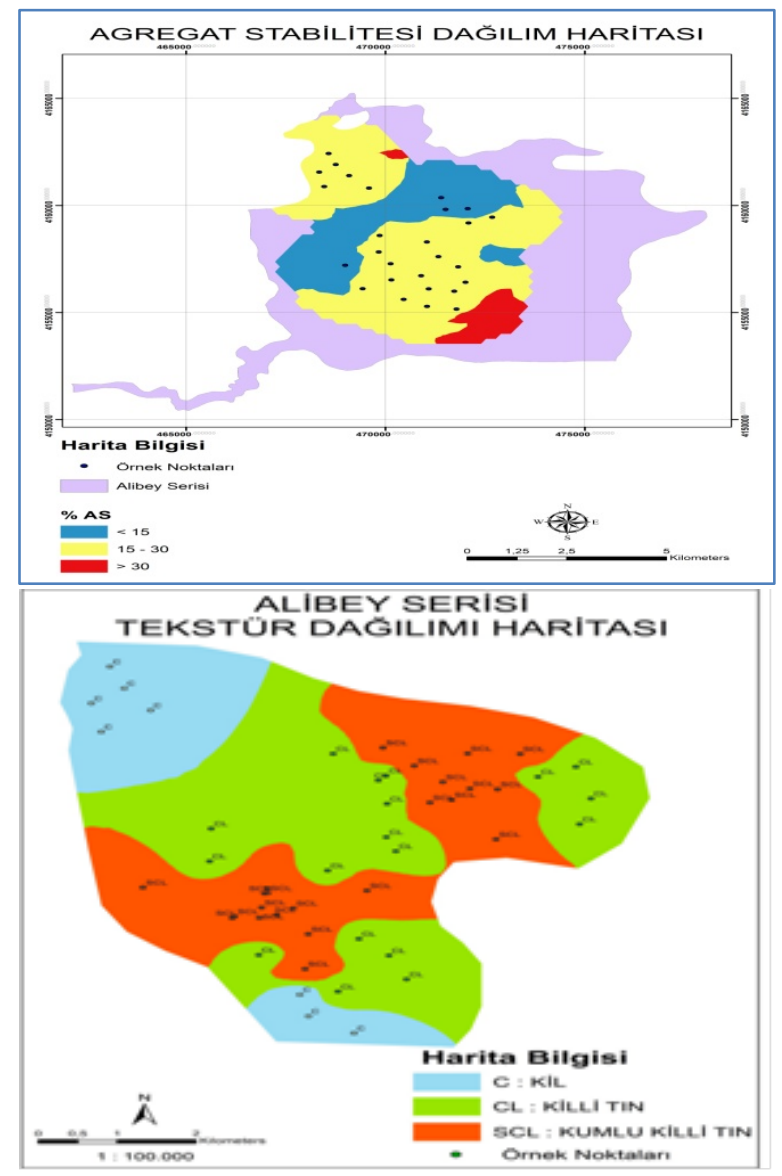

Şekil 2. Alibey serisi toprak agregat stabilitesi dağılım haritası

Şekil 3. Alibey serisi tekstür dağılım haritası

Şekil 2 ve 3'den görülebileceği gibi Alibey serisinde 27 noktadan yapılan örneklemede örnek noktalarının agregat stabilitesi değerleri \% 5.91 ile \% 41.40 arasında değişmiş, tekstür sınıfları ise C, CL ve SCL olarak belirlenmiştir.

Çalışma alanı topraklarının fiziksel ve kimyasal özelliklerindeki değişimler Tablo 1'de verilmiştir. Buna göre, toprakların kil içerikleri \% 22.70 ile \% 68.60 arasında, silt içerikleri \% 17.12 ile \% 38.40 arasında, kum içerikleri ise \% 13.45 ile \% 56.40 arasında, agregat stabilitesi değerleri \% 5.91 ile \% 41.40 arasında, organik madde içerikleri \% 0.82 ile \% 2,85 arasında, kireç içerikleri \% 6.80 ile \% 31.49 arasında, amonyum asetatta ekstrakte edilen sodyum değerleri $39.1 \mathrm{mg} \mathrm{kg}^{-1}$ ile $278.6 \mathrm{mg} \mathrm{kg}^{-1}$ arasında, potasyum değerleri $195.6 \mathrm{mg} \mathrm{kg}^{-1}$ ile $789.6 \mathrm{mg} \mathrm{kg}^{-1}$ arasında, kalsiyum değerleri $2527.2 \mathrm{mg} \mathrm{kg}^{-1}$ ile 3979.2 $\mathrm{mg} \mathrm{kg}^{-1}$ arasında ve magnezyum değerleri ise $433.3 \mathrm{mg} \mathrm{kg}^{-1}$ ile $1851 \mathrm{mg} \mathrm{kg}^{-1}$ arasında değişmiştir. 
Gümüş İ., Şeker C., Negiş H., Özaytekin HH., Karaarslan E., Çetin Ü.

Tablo 1. Araştırma Topraklarının Bazı Fiziksel ve Kimyasal Özelliklerinin Ortalama Değerleri ve İstatistiksel Analizleri *SS: Standart sapma; CV: Değiş̧im katsaylst

\begin{tabular}{|c|c|c|c|c|c|}
\hline Değişkenler & Ortalama & SS & $\% \mathrm{CV}$ & Min & Max \\
\hline \%Kil & 40,67 & 11,22 & 27,59 & 22,70 & 68,60 \\
\hline \%Kum & 32,21 & 11,68 & 36,28 & 13,45 & 56,40 \\
\hline OM \% & 1,56 & 0,49 & 31,57 & 0,82 & 2,85 \\
\hline \%Kireç & 11,26 & 6,45 & 57,28 & 6,80 & 31,49 \\
\hline Mg mg/kg & 865,8 & 344,9 & 39,84 & 433,3 & 1851,0 \\
\hline $\mathrm{Na} \mathrm{mg} / \mathrm{kg}$ & 92,4 & 58,3 & 63,06 & 39,1 & 278,6 \\
\hline $\mathrm{K} \mathrm{mg/kg}$ & 453,9 & 169,2 & 37,28 & 195,6 & 789,6 \\
\hline
\end{tabular}

Toprak özelliklerinin toprağın agregat stabilitesi üzerine etkilerini belirlemek için korelasyon analizi yapılmıştır. Buna göre; toprakların agregat stabilitesi ile kil miktarı arasında önemli $(\mathrm{P}<0.01)$ pozitif bir ilişki ( $\mathrm{R}^{2}$ : 0.82) elde edilmiştir. Aynı şekilde [13]'de topraktaki kil miktarı artışının istatistiki olarak agregasyonu etkilediğini belirtmektedir. [14] tarafindan yapılan bir çalışmada; agregat stabilitesi ve kil içeriği arasında önemli bir pozitif ilişki olduğu belirtilmektedir. Agregat stabilitesi üzerine kilin miktarı ve cinsi önemli etki yapmaktadır. Topraklarda agregat stabilitesinde sağlanacak daha güçlü bir etki düşük miktarda da olsa genellikle kil içeriği ile meydana gelmektedir. Genellikle kil miktarındaki artışa bağlı olarak agregat stabilitesinde de bir artış gözlenmektedir. Yüksek yüzey alanına sahip olan killer (montmorillonit) yüzey alanı düşük olan düşük olan killerle (kaolonit) karşılaştırıldığında agregat oluşumunda daha yüksek etkiye sahiptir [15].

Toprakların agregat stabilitesi ile organik madde miktarı arasında önemli $(\mathrm{P}<0.01)$ pozitif bir ilişki $\left(R^{2}: 0.52\right)$ elde edilmiştir. Organik madde toprağın üst kısmında agregat oluşum ve stabilitesi üzerinde önemli bir etkiye sahiptir. Organik maddenin agregasyondaki rolü, organik maddenin miktarından ziyade topraktaki ayrışma ve parçalanmadan ortaya çıkan polisakkaritler, proteinler, yağlar, mumlar, reçine gibi maddeler sebebiyledir. Organik maddenin agregat oluşumundaki etkisi kil yüzdesi düşük olan topraklarda daha belirgin olmaktadır [16]. Toprak organik maddesi ile agregat stabilitesi arasında yakın bir ilişki vardır, ancak agregat stabilitesi toplam organik maddeden çok ilave edilen tam ayrışmamış organik maddeyle daha fazla ilişkilidir [17].

Toprakların agregat stabilitesi ile değişebilir kalsiyum ve magnezyum içerikleri arasında önemli $(\mathrm{P}<0.01)$ pozitif bir ilişki $\left(\mathrm{R}^{2}: 0.52\right)$ elde edilmiştir. Değişebilir katyonların artışı ve azalması agregasyonu önemli ölçüde etkilemektedir. Kalsiyum ve magnezyum flokülasyonu artırıcı bir etkiye sahiptir. Flokülasyonun artışı ise agregat oluşumunu teşvik ederek, agregasyonun artmasına sebep olabilir. Yüksek $\mathrm{Ca}$ ve $\mathrm{Mg}$ doygunluğu, toprakta kolloidler arasında köprü oluşturarak ve biyolojik aktiviteyi artırarak agregat stabilitesini artırıcı etkide bulunabilmektedir [18].

Toprakların silt, kum, kireç, $\mathrm{K}$ ve $\mathrm{Na}$ oranları ile agregat stabilitesi arasında istatistiksel olarak önemli bir ilişki bulunmamıştır. Tane büyüklüğü ile özgül yüzey arasındaki ilişki nedeniyle, değişik büyüklükteki tanelerin topraktaki dağılım yüzdeleri önemli bir toprak özelliği niteliğindedir. Ayrıca tane büyüklüğü dağılımı, toprağın fiziksel, kimyasal ve biyolojik özellikleri hakkında tahminlerde bulunmaya yardım etmesi bitki ve toprak arasındaki ilişkileri etkilemesi yönünden de önemli bir toprak özelliğidir. Özgül yüzeylerinin düşük olması kumun toprak agregasyonunda olumsuz etkisini ortaya koymaktadır. [18] ve [12]; yaptıkları çalışmalarda toprakların silt miktarı ile agregasyon arasındaki istatistiki bakımdan 
önemsiz ilişkiler bulmuşlardır. Silt fraksiyonunun az veya fazla olması topraklarda agregasyonu azaltıcı veya arttırıcı yönde önemli bir etkiye sahip değildir [19]. [13], toprağın kireç içeriği, değişebilir Na ve K oranları ile agregasyon arasında önemli olmayan negatif bir ilişkiler bulmuştur. Değişebilir sodyum toprakta dispersiyonu artırarak agregasyonu azaltmaktadır [20].

\section{Sonuç}

Toprakların yapısal özelliklerinin geliştirilmesi ve korunması hem insan sağlı̆̆ı açısından hem de toprakların fiziksel, kimyasal ve biyolojik degredasyonunun önlenmesi açısından son derece önemlidir. Toprakların fiziksel özelliklerinin iyileştirilmesi toprak verimliliğinin önemli bir ögesi olan toprak fiziksel verimliliği açısından son derece olumludur. Toprakların yapısal olarak gelişimi çeşitli faktörlerin birlikte veya ayrı ayrı etkisi sonucu meydana gelmektedir. Araştırma alanı topraklarında agregasyonu artırmak için toprak üzerinde mekanizasyon faaliyetlerin minimum düzeyle sınırlandırılması, organik madde miktarının arttırılması ve toprak agregasyonuna olumsuz etkisi olabilecek her türlü faaliyetin azaltılarak fiziksel verimliliğin artırılması gerekmektedir.

\section{Teșekkür}

Bu araştırma TÜBITAK-1001 $112 \mathrm{O} 314$ nolu ve halen yürütülmekte olan projeden üretilmiştir.

\section{Kaynaklar}

[1] Akalan, İ., 1973. Toprak Fiziği. A.Ü.Z.F. Ders Kitabı No. 172. Ankara.

[2] Six, J., Elliot, E.T., Paustian, K., 2000. Soil Structure and Soil Organic Matter: A Normalized Stability Index and The Effect of Mineralogy. Soil Sci. Soc. Am. J. 64, 1042-1049.

[3] Özbek, H, Kaya, Z., Gök, M. ve Kaptan, H. 1999. Toprak Bilimi. Çukurova Üniversitesi Ziraat Fakültesi Ders Kitapları Yayınları, 73:A-16, 574-575, Adana.

[4] Coote, D.R., C.A. Malcom-McGovern, G.J. Wall, W.T. Dickenson and R.P. Rudra, 1988. Seasonal Variation of Erodibility Indices Based on Scholar Strength and Aggregate Stability in Some Ontario Soils. J. Soil Sci., 68: 405-416.

[5] www.kop.gov.tr (KOP, Tarım Eylem Planı)

[6] www.tuik.gov.tr

[7] Kemper, W.D., Rosenau, R.C. 1986. Aggregate Stability and Size Distribution, In A. Klute et al., Methods of Soil Analysis, part 1, Physical and Minerological Methods, pp.425-442, 2d ed. Agronomy Monograph 9, Soil Science Society of America, Madison.

[8] Gugino, B.K, Idowu O.J, Schindelbeck R.R., Van Es H.M., Wolfe D.W., Moebius-Clune, B.N., Thies J.E., and Abawi G.S. 2009. Cornell Soil Health Assessment Training Manual, Second Edition,Cornell University, Geneva, New York.

[9] Day, P.R., 1965. Particle Fractionation and Particle-Size Analysis. In: Methods of Soil Analysis, Part I, (Ed Black, C.A.), pp. 545-566. American Society of Agronomy, Madison, WI.Hillel, 1982. Introduction to Soil Physics. 2nd ed. Acedemic Pres, San Diego, CA.

[10] LECO Corporation. 2003. Truspec carbon/nitrogen determinator. Leco Corporation 3000. Lakeview Avenue, St Joseph, M1 49085-2396, USA. 
[11] U.S.Salinity Lab.Staff (1954). Diagnosis and İmprovement of Saline and Alkali Soils. U.S. Goverment Handbook No: 60, Printing Office, Washington.

[12] Minitab, 1995. Minitab Reference Manuel (Relase 7.1) Minitab Inc. State Coll. PA, 16801, USA.

[13] Anapalı, Ö. 1994. Iğdır Ovası Tuzlu-Sodyumlu Topraklarında Bazı Fiziksel ve Kimyasal Özelliklerin Agregasyon Üzerine Etkileri. Atatürk Ü. Zir. Fak. Der. 25 (3), 436-444.

[14] Wagner, S., Cattle, S.R., Scholten, T. and Felix-Henningsen, P., 2000. Observing the Evolution of Soil Aggregates From Mixtures of Sand, Clay and Organic Matter In Soil. New Zealand Society of Soil Science. 3: 217-218.

[15] Anonymous. 2003. Soil Quality Test Kit. Section II. Bacground\&Interpetive for Individual Tests. Page 2. http://sois.usda.gov/sqi/files/section2.pdf.

[16] Hillel, D., 1982. Introduction to Soil Physics. 2nd ed. Acedemic Pres, San Diego, CA.

[17] Shepherd, M.A., Harrison, R. and Webb, J., 2002. Managing Soil Organic Matter Implications for Soil Structure on Organic farms. Soil Use and Management 18: 284-292. Singh, J. and Kansal, B.D., 1985.

[18] Özbek, H, Kaya, Z., Gök, M. ve Kaptan, H. 1999. Toprak Bilimi. Çukurova Üniversitesi Ziraat Fakültesi Ders Kitapları Yayınları, 73:A-16, 574-575, Adana.

[19] Sönmez, K., 1980. Atatürk Üniversitesi Elazığ Çiftliğinde Toprakların Bazı Fiziksel ve Kimyasal Özelliklerin Agregasyon Üzerine Tesirleri İle İlgili Araştırmalar. Atatürk Üniv. Yay. No: 531, Ziraat Fakültesi Yayını No: 243.

[20] Canpolat, M.Y., 1990. Iğdır Yöresi Topraklarında Kaymak Sertliği (Kırılma Değeri) İle İlgili Araştırmalar. Doktora Tezi, Atatürk Üniv. Ziraat Fak., Erzurum. 